\title{
Thermal remote sensing from Airborne Hyperspectral Scanner data in the framework of the SPARC and SEN2FLEX projects: an overview
}

\author{
J. A. Sobrino ${ }^{1}$, J. C. Jiménez-Muñoz ${ }^{1}$, P. J. Zarco-Tejada ${ }^{2}$, G. Sepulcre-Cantó ${ }^{2}$, E. de Miguel $^{3}$, G. Sòria ${ }^{1}$, \\ M. Romaguera ${ }^{1}$, Y. Julien ${ }^{1}$, J. Cuenca ${ }^{1}$, V. Hidalgo ${ }^{1}$, B. Franch ${ }^{1}$, C. Mattar ${ }^{1}$, L. Morales ${ }^{4}$, A. Gillespie ${ }^{5}$, D. Sabol ${ }^{5}$, \\ L. Balick ${ }^{6}$, Z. Su ${ }^{7}$, L. Jia ${ }^{8}$, A. Gieske ${ }^{7}$, W. Timmermans ${ }^{7}$, A. Olioso ${ }^{9}$, F. Nerry ${ }^{10}$, L. Guanter ${ }^{11}$, J. Moreno ${ }^{11}$, and \\ Q. Shen ${ }^{1}$ \\ ${ }^{1}$ Global Change Unit, Image Processing Laboratory, University of Valencia, Spain \\ ${ }^{2}$ Instituto de Agricultura Sostenible, Consejo Superior de Investigaciones Científicas, Córdoba, Spain \\ ${ }^{3}$ Instituto Nacional de Técnia Aeroespacial, Dpto. de Observación de la Tierra, Teledetección y Atmósfera, Madrid, Spain \\ ${ }^{4}$ Dpto. de Ciencias Ambientales y Recursos Naturales, Facultad de Ciencias Agronomicas, Universidad de Chile, \\ Santiago de Chile, Chile \\ ${ }^{5}$ W. M. Keck Remote Sensing Laboratory, Dept. of Earth and Space Sciences, University of Washington, Seattle, USA \\ ${ }^{6}$ Space and Remote Sensing Sciences Group, Los Alamos National Laboratory, Los Alamos, USA \\ ${ }^{7}$ International Institute for Geoinformation Science and Earth Observation (ITC), Enschede, The Netherlands \\ ${ }^{8}$ Alterra, Wageningen University and Research Centre, Wageningen, The Netherlands \\ ${ }^{9}$ INRA Bioclimatologie, Avignon, France \\ ${ }^{10}$ LSIIT/TRIO, Louis Pasteur University, Illkirch cedex, France \\ ${ }^{11}$ Laboratory of Earth Observation, Image Processing Laboratory, University of Valencia, Spain
}

Received: 17 Febuary 2009 - Published in Hydrol. Earth Syst. Sci. Discuss.: 5 June 2009

Revised: 3 September 2009 - Accepted: 20 October 2009 - Published: 3 November 2009

\begin{abstract}
The AHS (Airborne Hyperspectral Scanner) instrument has 80 spectral bands covering the visible and near infrared (VNIR), short wave infrared (SWIR), mid infrared (MIR) and thermal infrared (TIR) spectral range. The instrument is operated by Instituto Nacional de Técnica Aerospacial (INTA), and it has been involved in several field campaigns since 2004 .

This paper presents an overview of the work performed with the AHS thermal imagery provided in the framework of the SPARC and SEN2FLEX campaigns, carried out respectively in 2004 and 2005 over an agricultural area in Spain. The data collected in both campaigns allowed for the first time the development and testing of algorithms for land surface temperature and emissivity retrieval as well as the estimation of evapotranspiration from AHS data. Errors were found to be around $1.5 \mathrm{~K}$ for land surface temperature and $1 \mathrm{~mm} /$ day for evapotranspiration.
\end{abstract}

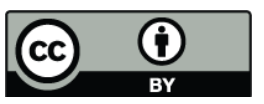

Correspondence to: J. A. Sobrino (sobrino@uv.es)

\section{Introduction}

Although remote sensing is recognized as a powerful tool in the collection, analysis, and modeling of environmental data, less attention has been given to the use of thermal infrared (TIR) remote sensing. With the launch of the NASA Terra suite of Earth remote sensing instruments in 1999, which included TIR sensors, thermal data are poised to become a major source of quantitative and qualitative information on land surface processes and for their characterization, analysis and modelling (Quattrochi and Luvall, 2004). Currently, medium spatial resolution TIR data $(\sim 100 \mathrm{~m})$ are provided by TERRA/ASTER and Landsat/TM-ETM+, although its continuity in the future is uncertain. Low resolution TIR data $(>1 \mathrm{~km})$ is currently provided by many sensors, such as TERRA-AQUA/MODIS, NOAA-MetOp/AVHRR, MSGSEVIRI, ENVISAT/AATSR, etc. Its continuity in the future is ensured with NOAA/NASA NPOESS program and also with the future ESA's Sentinels. High resolution TIR data (few meters) are currently only available previous ondemand flights, in which multispectral sensors are placed on

Published by Copernicus Publications on behalf of the European Geosciences Union. 
board planes. This is the case of the imagery used in this paper, as will be shown bellow.

There are two fundamental reasons why TIR data contribute to an improved understanding of land surface processes: i) through measurement of surface temperatures as related to specific landscape and biophysical components, and ii) through relating surface temperatures with energy fluxes for specific landscape phenomena or processes (Quattrochi and Luvall, 1999). Different thematic areas where TIR remote sensing data have been applied to the analysis of landscape attributes or land surface processes could be found, as for example: i) landscape characterization; ii) thermal intertia and landscape analysis; iii) estimation of energy fluxes; iv) evaporation/evapotranspiration/soil moisture; v) quantification of energy balance or energy flux; and vi) forest energy exchange. Another important applications of TIR remote sensing are climate applications (soil thaw/freeze cycle characterization, drought monitoring...), thermal anomalies (urban heat island) and high temperature events detection (forest fires, coal seam fires, burning oil spills or natural phenomena such as volcanoes...).

In all these thematic areas and other environmental studies, land surface temperature (LST) is a key parameter which can be retrieved from TIR data. Hence, except for solar irradiance components, most of the fluxes at the surface/atmosphere interface can only be parameterized through the use of surface temperature. LST can play either a direct role, such as when estimating long wave fluxes, or indirectly as when estimating latent and sensible heat fluxes (Kerr et al., 2004). LST can be also used as an input data in water and energy balance studies, which is an important issue in environmental studies in order to achieve a better understanding on the exchange of heat and moisture between the land surface and lower atmosphere, also leading to a better understanding on the water and carbon cycles. Moreover, many other applications rely on the knowledge of LST, such as geology, hydrology, vegetation monitoring, global circulation models, and evapotranspiration, among others.

The purpose of this paper is to present an overview of the results obtained from thermal remote sensing in the framework of two field campaigns carried out over an agricultural area in Spain. Further details on the results presented in this overview can be found in Sobrino et al. (2006) and Sobrino et al. (2008).

The paper is organized as follows: Sect. 2 provides a description of the field campaigns, the study area, the instrumentation and measured in situ data and the airborne imagery collected. Section 3 describes the algorithms developed for LST retrieval, whereas Sect. 4 shows the procedure considered to estimate the evapotranspiration. Finally, Sect. 5 presents a summary and conclusions.

\section{Methods}

\subsection{SPARC and SEN2FLEX field campaigns}

In the framework of its Earth Observation Envelope Programme (EOEP), the European Space Agency (ESA) carries out a number of ground-based and airborne campaigns to support geo/biophysical algorithms development, calibration/validation activities and simulation of future spaceborne Earth Observation (EO) missions. The SPECTRA Barrax Campaign (SPARC) and the Sentinel-2 and Fluorescence Experiment (SEN2FLEX) are samples of these field campaigns. Both of them were conducted in the Spanish agricultural area of Barrax, which is described in the next section.

The SPARC field campaign started in July 2003, but the main data collection was carried out in July 2004. It was organized under the framework of different activities related to the Surface Processes and Ecosystem Changes Through Response Analysis (SPECTRA), an ESA candidate Core Earth Explorer mission selected for phase-A studies but finally rejected for phase-B. Ground-based measurements included vegetation, atmospheric and radiometric parameters, among others. Different satellite and airborne imagery were also collected during the campaign. Detailed information can be found in Moreno et al. (2004). In this paper we will focus on thermal radiometric measurements, which will be described in Sect. 2.3, and thermal infrared airborne imagery, which will be described in Sect. 2.4.

SEN2FLEX is a campaign that combines different activities in support of initiatives related both to fluorescence experiments to observe solar induced fluorescence signal over multiple surface targets, and to Global Monitoring for Environment and Security (GMES) Sentinel-2 initiative for prototyping spectral bands, spectral widths, and spatial/temporal resolutions to meet mission requirements. The first initiative is closely related to previous analysis in the framework of the Fluorescence Explorer (FLEX) mission, an ESA candidate for a future Earth Explorer mission. Furthermore, SEN2FLEX campaign includes activities in support of the EU Water Framework Directive (WFD) EO projects in order to improve Europe's water resources protection and management. Similarly to SPARC campaign, coordinated collection of satellite, airborne hyperspectral and coincident in-situ data together with analysis of the joint dataset was also carried out in SEN2FLEX. Two campaigns at different time period during the year 2005 were carried out to ensure different crop growth stages and conditions: the first on 1,2, and 3 June 2005 and the second on 12, 13 and 14 July 2005. Details can be found in http://www.uv.es/ leo/sen2flex. Details on thermal in-situ measurements and thermal imagery will be provided in Sects. 2.3 and 2.4. 


\subsection{Study area: the agricultural site of Barrax}

Field measurements and airborne imagery were collected in the agricultural area of Barrax $\left(39^{\circ} 3^{\prime} \mathrm{N}, 2^{\circ} 6^{\prime} \mathrm{W}, 700 \mathrm{~m}\right)$. This study area is located in Albacete (Spain). The area has been selected in many other experiments due to its flat terrain, minimising the complications introduced by variable lighting geometry, and the presence of large, uniform land-use units, suitable for validating moderate-resolution satellite image products.

Barrax has a Mediterranean type climate, with heavy rainfall in spring and autumn and lower in summer; it presents a high level of continentality, with quite sudden changes from cold months to warm months and high thermal oscillations in all seasons between the maximum and minimum daily temperatures.

The soils of the area are Inceptisols in terms of soil Taxonomy. About $65 \%$ of cultivated lands at Barrax are dryland (67\% winter cereals; $33 \%$ fallow) and 35\% irrigated land $(75 \%$ corn; $15 \%$ barley/sunflower; $5 \%$ alfalfa; $5 \%$ onions and vegetables). The University of Castilla-La Mancha, through the Escuela Técnica Superior de Ingenieros Agrónomos (Agronomic Engineers Technical Institute) operates three agro-meteorological stations in the study area. More details about the test site are presented in Moreno et al. (2001).

\subsection{Instrumentation and in-situ data collection}

Radiometric temperatures were measured in situ in order to retrieve surface temperatures and emissivities. For this purpose, different thermal radiometers (single broadband and also multiband) and thermal cameras were used, jointly with blackbodies for calibration purposes and a diffuse reflectance standard plate (model Labsphere Infragold) to estimate the sky irradiance. In particular, the CIMEL radiometer model CE 312-2, with five TIR narrowbands and also with a broadband $(8-14 \mu \mathrm{m})$ allowed the retrieval of surface temperature and emissivity using the Temperature and Emissivity Separation (TES) algorithm (Gillespie et al., 1998). TES emissivities for the broadband were then used to recover surface temperatures from the broadband radiometers. In this way, a complete dataset of LSTs measured in situ over different samples (water, bare soil, green grass, senescent vegetation, corn, wheat) was acquired in both SPARC and SEN2FLEX field campaigns. This dataset was used to validate algorithms for LST retrieval from AHS data.

\subsection{Airborne Hyperspectral Scanner (AHS)}

\subsubsection{Technical description}

The Airborne Hyperspectral Scanner (AHS) (developed by SensyTech Inc., currently ArgonST, USA) is operated by the Spanish Institute of Aeronaoutics (INTA), onboard its aircraft CASA 212-200 Paternina. The AHS incorporates advanced components to ensure high performance while maintaining the ruggedness to provide operational reliability in a survey aircraft. The main AHS technical specifications are:

- Optical design: scan mirror plus Cassegrain-type afocal telescope with a single IFOV determining field stop (Pfund assembly),

- FOV (Field Of View)/IFOV (Instantaneous Field Of View): $90^{\circ} / 2.5 \mathrm{mrad}$,

- GSD (Ground Sampling Distance): $2.1 \mathrm{mrad}\left(0.12^{\circ}\right)$,

- Scan rates: $12.5,18.75,25,35 \mathrm{~Hz}$, with corresponding ground sampling distances from 7 to $2 \mathrm{~m}$,

- Digitization precision: 12 bits to sample the analog signal, with gain level from $\times 0.25$ to $\times 10$,

- Samples per scan line: 750 pixels/line,

- Reference sources: two controllable thermal black bodies ("cold" and "hot") placed at the edges of the field of view acquired each scanline,

- Spectrometer: four dichroic filters to split radiation in four optical ports (VIS/NIR, SWIR, MIR and TIR), and diffraction gratings within each port, plus lens assemblies for re-focusing light onto the detectors,

- Detectors: Si array for VIS/NIR port; InSb and MCT arrays, cooled in $\mathrm{N}_{2}$ dewars, for SWIR, MIR and TIR ports,

- Spectral bands: 80 bands, with continuous coverage in four spectral regions (VNIR, SWIR, MIR and TIR) + single band at 1.5 micrometers. In particular, 10 TIR thermal bands, from 71 to 80 , with effective wavelengths provided in Table 1.

- Noise Equivalente Delta Temperature (NE $\Delta T$ ) for TIR bands $\sim 0.25^{\circ} \mathrm{C}$ (depends on the band considered).

\subsubsection{Imagery dataset}

During the SPARC and SEN2FLEX campaigns the AHS collected several images at different times (including also nighttime acquisitions in the case of SEN2FLEX) and altitudes. In particular, four different flights altitudes were considered: $975 \mathrm{~m}, 1370 \mathrm{~m}, 2060 \mathrm{~m}$ and $2745 \mathrm{~m}$ above ground level, which provides pixel sizes of $2 \mathrm{~m}, 3 \mathrm{~m}, 4 \mathrm{~m}$ and $7 \mathrm{~m}$, respectively. A total amount of 18 images were acquired in SPARC and 24 images in SEN2FLEX.

\subsubsection{Processing}

Basic processing (pre-processing) of AHS imagery included the conversion of digital counts to radiance units and the atmospheric correction. Then, a higher processing level was applied to retrieve LST and heat fluxes, as will be explained in next sections. INTA provided the AHS imagery processed to at-sensor radiances (level 1b) and also the Image Geometry Model (IGM) files required to perform the geometric 
correction. Imagery was atmospherically corrected in the VNIR and TIR spectral regions, using atmospheric profiles collected during the campaign and the MODTRAN4 radiative transfer code. In the case of VNIR, the atmospheric correction (conversion of at-sensor radiances to surface reflectances) was performed according to the method described in Guanter et al. (2005). For the TIR bands, at-sensor radiance was converted to at-surface radiance after compensation of atmospheric transmissivity and up-welling radiance. Since bands 71 and 80 are more affected by noise and band 74 is located in the ozone absorption region (despite this absorption is not observed at the flights altitude), bands $72,73,75$, $76,77,78$ and 79 (see Table 1) were finally considered as the optimal ones.

\subsubsection{Vicarious calibration of thermal bands}

Since the main objective is to retrieve LST from AHS TIR bands, a previous assessment of the calibration for these bands was performed using the data collected in situ. This previous analysis allowed the identification of a technical problem for bands $71(8.18 \mu \mathrm{m}), 72(8.66 \mu \mathrm{m})$ and 73 $(9.15 \mu \mathrm{m})$ during the SPARC campaign in 2004. For this reason, only bands from 75 to 79 (see Table 1) were considered as optimal. Fortunately, this technical problem was solved in 2005 for the SEN2FLEX campaign, and the comparison between at-sensor brightness temperatures extracted from the AHS TIR bands and the ones simulated from the in situ data for 97 test points (including water, vegetation and bare soil) provided a Root Mean Square Error (RMSE) $<1.5 \mathrm{~K}$.

\section{Algorithms development for land surface temperature and emissivity retrievals}

\subsection{Theoretical framework}

Methods for LST retrieval are based on the radiative transfer equation, which can be written in the thermal infrared region for a certain sensor band " $i$ " as:

$L_{i}\left(T_{i}\right)=L_{i}^{\mathrm{LLR}} \tau_{i}+L_{i}^{\uparrow}$

where $L_{i}\left(T_{i}\right)$ is the radiance measured by the sensor $\left(T_{i}\right.$ is the at-sensor brightness temperature), $\tau_{i}$ is the atmospheric transmissivity and $L_{i}^{\uparrow}$ is the up-welling path radiance. The term $L^{\mathrm{LLR}}$ is the land-leaving radiance (LLR) or radiance measured at ground-level, which is given by:

$L_{i}^{\mathrm{LLR}}=\varepsilon_{i} B_{i}\left(T_{s}\right)+\left(1-\varepsilon_{i}\right) \frac{F_{i}^{\downarrow}}{\pi}$

where $\varepsilon_{i}$ is the surface emissivity, $B_{i}\left(T_{S}\right)$ is the Planck radiance at surface temperature $T_{s}$ and $F_{i}^{\downarrow}$ is the down-welling sky irradiance. In Eq. (2) the assumption of lambertian behaviour for the surface has been considered in order to express the reflection term as $(1-\varepsilon) \pi^{-1} F^{\downarrow}$. The magnitudes
Table 1. Effective wavelengths for AHS thermal infrared bands.

\begin{tabular}{cc}
\hline AHS Band & $\begin{array}{c}\text { Effective Wavelength } \\
(\mu \mathrm{m})\end{array}$ \\
\hline 71 & 8.18 \\
72 & 8.66 \\
73 & 9.15 \\
74 & 9.60 \\
75 & 10.07 \\
76 & 10.59 \\
77 & 11.18 \\
78 & 11.78 \\
79 & 12.35 \\
80 & 12.93 \\
\hline
\end{tabular}

involved in Eqs. (1) and (2) are band averaged values using the spectral response functions.

\subsection{Single-channel method}

Single-channel methods retrieve LST only from one thermal band. Different single-channel algorithms can be found in the literature (see for example Qin et al., 2001; JiménezMuñoz and Sobrino, 2003). In this paper we propose a single-channel algorithm based on the solving for the Planck radiance according to Eqs. (1) and (2):

$B_{i}\left(T_{S}\right)=\frac{L_{i}\left(T_{i}\right)-L_{i}^{\uparrow}}{\varepsilon_{i} \tau_{i}}-\frac{\left(1-\varepsilon_{i}\right) F_{i}^{\downarrow} / \pi}{\varepsilon_{i}}$

LST can be finally retrieved by inversion of the Planck's law:

$T_{s}=\frac{c_{2}}{\lambda_{i}}\left[\ln \left(\frac{c_{1}}{\lambda_{i}^{5} B_{i}}+1\right)\right]^{-1}$

where $B_{i}$ is given by Eq. (3) and $c_{1}$ and $c_{2}$ are the constants in the Planck's function $\left(c_{1}=1.19104 \times 10^{8} \mathrm{~W} \mu \mathrm{m}^{4} \mathrm{~m}^{-2} \mathrm{sr}^{-1}\right.$ and $c_{2}=14387.7 \mu \mathrm{m} \mathrm{K}$ ). In this method the surface emissivity $\varepsilon_{i}$ is assumed to be known. The optimal AHS band for applying a single-channel algorithm is band $75(10.07 \mu \mathrm{m})$, since it shows the highest atmospheric transmissivity. Assuming that atmospheric water vapour is the primary factor controlling the magnitude of atmospheric transmittance, the hemispheric down-welling radiance and up-welling atmospheric radiance for a given band, different approaches can be proposed in order to related these atmospheric parameters with the atmospheric water vapour, which is a more easily accessible parameter. In the case of SPARC 2004, such approaches leaded to a Root Mean Square Error (RMSE) on LST of 1.6 K. In the case of SEN2FLEX 2005, atmospheric parameters were computed directly from MODTRAN ouputs, therefore empirical approaches with water vapour were not considered. The RMSE obtained was $<1.7 \mathrm{~K}$ (test plots described in Sect. 2.3). 


\subsection{Two-channel (split-window) technique}

The second method proposed for LST retrieval is the TwoChannel (TC) technique, also called Split-Window (SW) when working in 10-12 $\mu \mathrm{m}$, which has been widely used by the scientific community (see for example Kerr et al., 2004). In this case we have considered the $\mathrm{TC}$ algorithm proposed by Sobrino and Raissouni (2000):

$$
\begin{aligned}
T_{s} & =T_{i}+a_{1}\left(T_{i}-T_{j}\right)+a_{2}\left(T_{i}-T_{j}\right)^{2}+a_{0} \\
& +\left(a_{3}+a_{4} w\right)(1-\varepsilon)+\left(a_{5}+a_{6} w\right) \Delta \varepsilon
\end{aligned}
$$

being $T_{i}$ and $T_{j}$ the at-sensor brightness temperatures (in $\mathrm{K}$ ) for two different AHS TIR bands, $w$ is the atmospheric water vapour content (in $\mathrm{g} / \mathrm{cm}^{2}$ ) and $\varepsilon=0.5\left(\varepsilon_{i}+\varepsilon_{j}\right)$ and $\Delta \varepsilon=\varepsilon_{i}-\varepsilon_{j}$ ) are respectively the mean emissivity and the emissivity difference for the two AHS bands considered. As it can be noticed, this method requires two TIR bands. Optimal AHS bands for applying a split-window algorithm are bands 75 $(10.07 \mu \mathrm{m})$ and $79(12.35 \mu \mathrm{m})$, as was proposed in Sobrino et al. (2006). In this case, the knowledge of the surface emissivity for the two bands is also required. The coefficients $a_{i}(i=0,6)$ are obtained from simulated data (atmospheric soundings, MODTRAN-4 and emissivity spectra). The comparison against in situ data provided $\mathrm{RSME}<1.9 \mathrm{~K}$ in both SPARC 2004 and SEN2FLEX 2005 campaigns.

\subsection{Temperature and Emissivity Separation (TES) algorithm}

Temperature and Emissivity Separation (TES) algorithm was developed by Gillespie et al. (1998), and it is used to produce the Standard Products of LST and LSE from the Advanced Spaceborne Thermal Emission and Reflection Radiometer (ASTER) data. The TES algorithm provides simultaenously LST and emissivity, and requires at least 4 or 5 TIR bands. It uses as input the land-leaving radiances and the downwelling atmospheric radiance, and it is composed by three different modules: NEM (Normalized Emissivity Method), RATIO and MMD (Maximum-Minimum Difference). Basically, the NEM module provides a first guess of the surface temperature and emissivities using an iterative procedure, the RATIO module normalizes the surface emissivities providing the so-called beta spectrum, and finally the MMD module recovers final surface emissivities and temperature using a semi-empirical relationship bewteen minimum emissivity $\left(\varepsilon_{\min }\right)$ and spectral contrast (MMD), $\varepsilon_{\min }=a+b \times \mathrm{MMD}^{c}$.

Different bands configurations (Config) have been considered to apply the TES method to AHS TIR data (see Table 1):

Config 1: AHS bands $75,76,77,78,79$,

Config 2: AHS bands 72,73,75,76,77,78,79,

Config 3: AHS bands 71,72,73,74,75,76,77,78,79,80.

Config 1 was the one used in SPARC 2004, since the other bands were affected by the technical problem discussed in

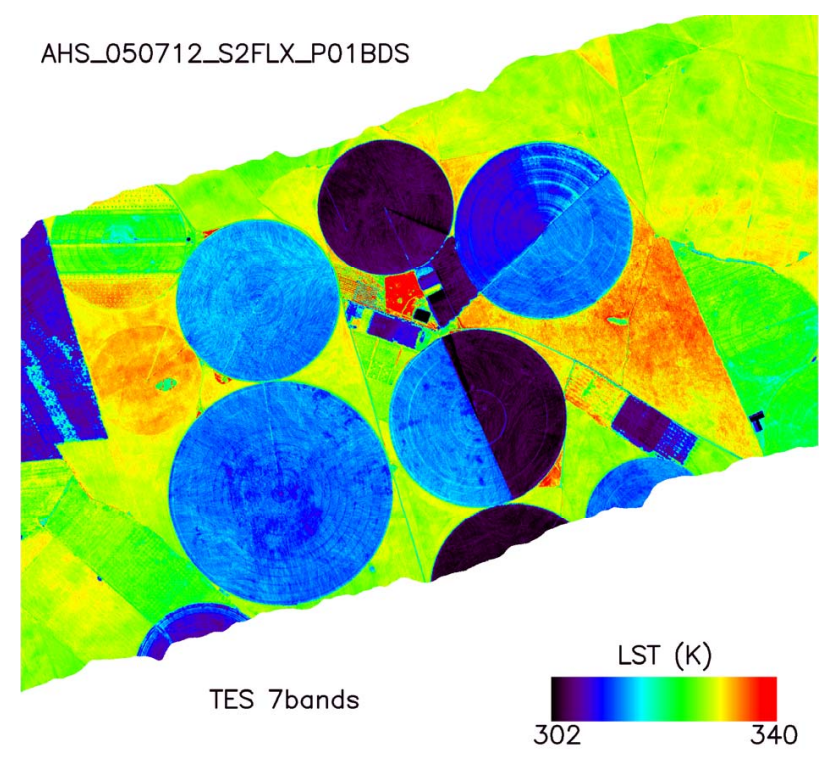

Fig. 1. Land Surface Temperature (LST) map obtained with the Temperature and Emissivity Separation (TES) algorithm applied to Airborne Hyperspectral Scanner (AHS) data in the SEN2FLEX 2005 field campaign.

Sect 2.4.4. In SEN2FLEX 2005 the three different configurations were applied in order to assess the effect on the LST retrieval depending on the number of TIR band used. A RMSE=1.4 K was obtained in SPARC 2004 using only Config 1. In SEN2FLEX 2005 a RMSE $<1.6 \mathrm{~K}$ was obtained for the three configurations. As an example, Fig. 1 shows a LST map obtained with the TES algorithm during SEN2FLEX 2005. Spectral emissivity retrievals from AHS data using other multichannel TES methods are also presented in Jiménez et al. (2007).

\section{Simplified method for evapotranspiration estimation}

Evapotranspiration refers to the water lost from soil surface (evaporation) and from crop (transpiration). The knowledge of ET allows the irrigation water use optimisation. It is important to remark that ET estimation by solving the energy balance equation requires the availability of TIR data.

Daily ET has been retrieved according to the methodology presented in Sobrino et al. (2005) and Gómez et al. (2005), which is based on the Simplified Surface Energy Balance Index (S-SEBI) model (Roerink et al., 2000). Hence, the instantaneous evapotranspiration $\left(\mathrm{ET}_{i}\right)$ is given by:

$\operatorname{LET}_{i}=\Lambda_{i}\left(R_{n i}-G_{i}\right)$

where $\Lambda$ is the evaporative fraction, $R_{n}$ is the net radiation and $G$ is the soil heat flux. The subindex " $i$ " refers to "instantaneous" values, whereas the subindex " $d$ " is 


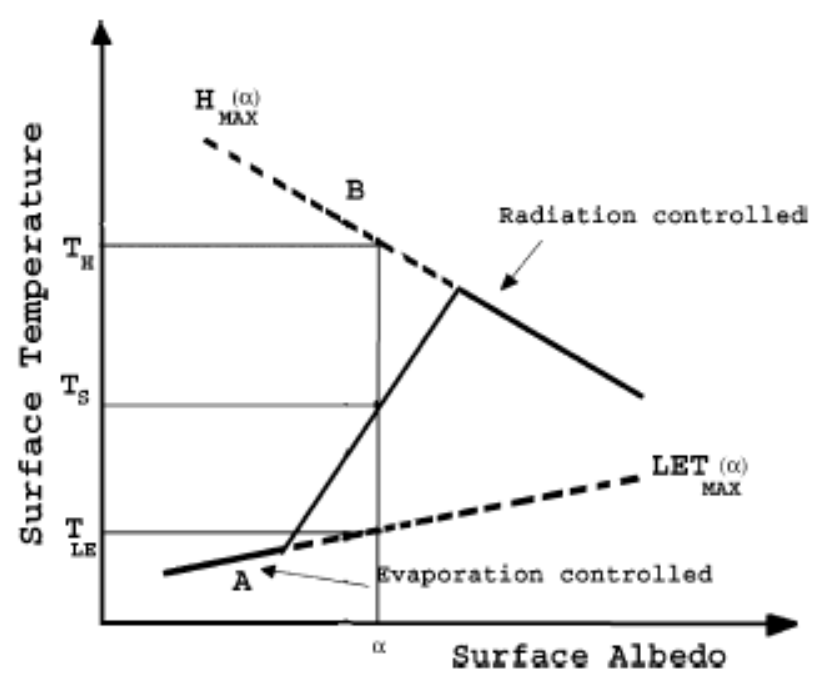

Fig. 2. Surface temperature versus surface albedo. $H$ is the sensible heat flux, LET is the latent heat flux and $\alpha$ is the albedo (adapted from Roerink et al., 2000).

employed for "daily" values. Then, daily ET $\left(\mathrm{ET}_{d}\right)$ can be obtained as:

$\mathrm{ET}_{d}=\frac{\Lambda_{i} C_{d i} R_{n i}}{L}$

where $L$ is the latent heat of vaporization $\left(2.45 \mathrm{MJ} \mathrm{kg}^{-1}\right)$ and $C_{d i}$ is the ratio between daily and instantaneous $R_{n}$, $C_{d i}=R_{n d} / R_{n i}$ (Seguin and Itier, 1983; Wassenaar et al., 2002), which is day and year dependent (Bastiaanssen et al., 2002). It has been estimated from measurements of net radiation registered in a meteorological station located in the Barrax area. In the step from Eqs. (6) to (7) the assumption $\Lambda_{i} \approx \Lambda_{d}$ and $G_{d} \approx 0$ has been considered.

Instantaneous net radiation $\left(R_{n i}\right)$ is obtained from the balance between the incoming and outgoing shortwave and longwave radiation:

$R_{n i}=\left(1-\alpha_{s}\right) R_{s w}^{\downarrow}+\varepsilon R_{l w}^{\downarrow}-\varepsilon \sigma T_{S}^{4}$

where $\alpha_{s}$ is the surface albedo, $R_{s w}^{\downarrow}$ and $R_{l w}^{\downarrow}$ are respectively shortwave and longwave incoming radiation (measured in meteorological stations), $\varepsilon$ and $T_{s}$ are respectively surface emissivity and temperature (estimated with any of the method presented in the previous section) and $\sigma$ is the Stefan-Boltzmann constant $\left(5.670 \times 10^{-8} \mathrm{~W} \mathrm{~m}^{-2} \mathrm{~K}^{-4}\right)$. Surface albedo has been estimated from a weighted mean of atsurface reflectivities ( $\left.\rho^{\text {surface }}\right)$ estimated with AHS VNIR atmospherically corrected bands:

$\alpha_{s}=\sum_{i=1}^{20} \omega_{i} \rho_{i}^{\text {surface }}$

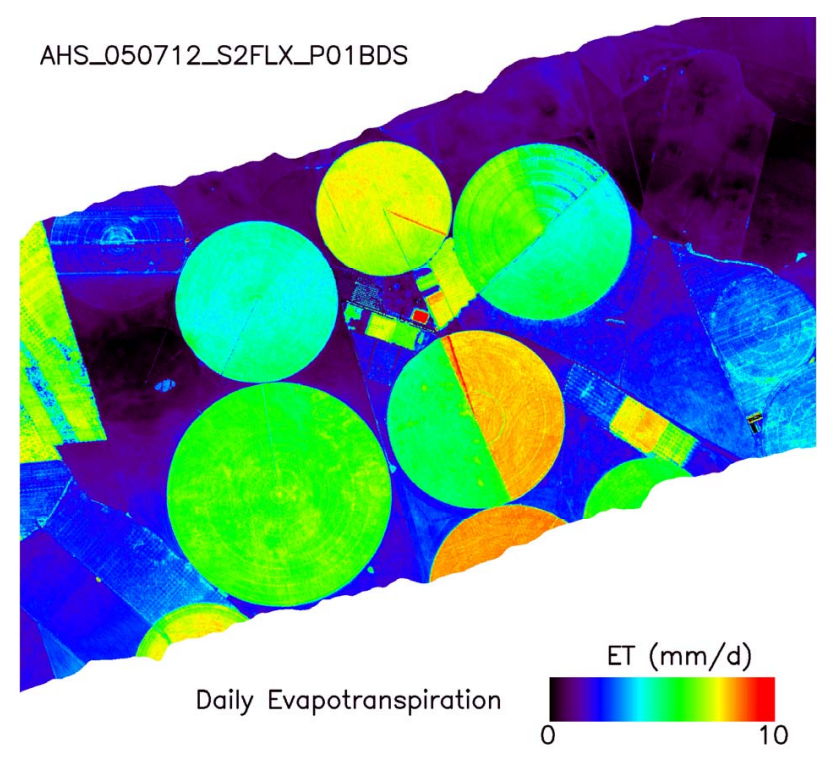

Fig. 3. Daily Evapotranspiration (ET) map obtained from Airborne Hyperspectral Scanner (AHS) data in the SEN2FLEX 2005 field campaign.

where $\omega_{i}(i=1,20)$ are the weight factors obtained from the solar irradiance spectrum at the top of the atmosphere. Finally, the evaporative fraction is estimated as:

$\Lambda_{i}=\frac{T_{H}-T_{s}}{T_{H}-T_{\mathrm{LET}}}$

where $T_{H}$ and $T_{\mathrm{LET}}$ are two characteristic temperatures obtained from the graph of surface temperature versus surface albedo (Roerink et al., 2000), and corresponding to dry and wet conditions for a given albedo value (see Fig. 2). According to Roerink et al. (2000), Eq. (10) is only applicable when the atmospheric conditions are constants over the image and the study site includes simultaneously wet and dry areas. In Fig. 2 it is observed an approximately constant surface temperature $\left(T_{S}\right)$ for low albedo values, related to water saturated surfaces like open water and irrigated lands, where all available energy is used in evaporation process. On the other hand, for higher albedo values the figure shows an increase of surface temperature with albedo. Thus, from A to $\mathrm{B}$ the temperature increase because of the change in the surface temperature is a result of less soil moisture availability yields an evapotranspiration decrease and therefore a surface temperature increase. Here surface is said to be "Evaporation controlled". Finally, surface temperature from B decreases with increasing albedo. In this point, the soil moisture decrease such as no evaporation can occur due to that all available energy is used for surface heating. Thus an albedo increase yields a net radiation decrease and therefore less surface heating. Here, surface temperature is said to be "Radiation Controlled". The methodology was applied to the AHS imagery and tested using ET values measured 
in situ in a lysimeter station located in a green grass plot. A RMSE $\sim 1 \mathrm{~mm} /$ day was obtained. Figure 3 shows an example of daily ET map obtained from AHS data in the SEN2FLEX campaign.

\section{Summary and conclusions}

Field campaigns, as for example SPARC and SEN2FLEX, offer an excellent opportunity to collect different groundbased measurements and also to validate different algorithms for the retrieval of bio-geophysical parameters from remote sensing data of interest in environmental studies.

In this paper we have presented an overview of the analysis of thermal remote sensing data acquired by the AHS sensor, with 10 thermal bands in the range $8-13 \mu \mathrm{m}$, which allows the retrieval of land surface temperature (LST), emissivity and evapotranspiration (ET) in combination with VNIR bands. Errors on LST are within $1.5 \mathrm{~K}$, whereas errors on ET are within $1 \mathrm{~mm} /$ day.

With the results presented in this paper we hope to modestly contribute to the scientific discussion regarding to usefulness of TIR data and its availability in the future sensors.

Acknowledgements. We thank to the European Union (CEOPAEGIS, project FP7-ENV-2007-1 Proposal No. 212921; WATCH, project 036946), the Ministerio de Ciencia y Tecnología (EODIX, project AYA2008-0595-C04-01) and the European Space Agency (SPARC, project 18307/04/NL/FF; SEN2FLEX, project RFQ 3-11291/05/I-EC) for the financial support. We also thank the INTA team for the preprocessing of the AHS imagery and their technical assistance.

Edited by: J. Wen

\section{References}

Bastiaanssen, W. G. M., Molden, D. J., and Makin, I. W.: Remote sensing for irrigated agriculture: Examples from research and posible applications, Agr. Water Manage., 46, 137-155, 2000.

Gillespie, A., Rokugawa, S., Matsunaga, T., Cothern, J. S., Hook, S., and Kahle, A. B.: A temperature and emissivity separation algorithm for advanced spaceborne thermal emission and reflection radiometer (ASTER) images, IEEE T. Geoscie. Remote, 36, 1113-1126, 1998.

Gómez, M., Sobrino, J. A., Olioso, A., and Jacob, F.: Retrieval of evapotranspiration over the Alpilles/ReSeDA experimental site using airborne POLDER sensor and Thermal Camera, Remote Sens. Environ., 96(3-4), 399-408, 2005.

Guanter, L., Richter, R., Alonso, L., and Moreno, J.: Atmospheric correction algorithm for remote sensing data over land. II. Application to ESA SPARC campaigns: airborne sensors, Proceedings of the SPARC, Enschede, Holland, 4-5 July, ESA Publications Division, WPP-250, 2005.
Jiménez-Muñoz, J. C. and Sobrino, J. A: A generalized singlechannel method for retrieving land surface temperature from remote sensing data, J. Geophys. Res., 108(D22), 4688, doi:10.1029/2003JD003480, 2003.

Jiménez, M., Chico, J., de Miguel, E., Gómez, J. A., Sobrino, J. A., Jiménez-Muñoz, J. C., Prado, E., and Robles, C: Airborne Hyperspectral Scanner (AHS) spectral emissivity retrieval in $8-13 \mu \mathrm{m}$, 10th International Symposium on Physical Measurements and Sigantures in Remote Sensing (ISPMSRS'07), Davos, Switzerland, 12-14 March, International Society for Photogrammetry and Remote Sensing (ISPRS), 2007.

Kerr, Y. H., Lagouarde, J. P., Nerry, F., and Ottlé, C.: Land surface temperature retrieval techniques and applications: case of the AVHRR. Thermal Remote Sensing in Land Surface Processes, edited by: Quattrochi, D. A. and Luvall, J. C., CRC Press, Florida, 33-109, 2004.

Moreno, J., Caselles, V., Martínez-Lozano, J. A., Meliá, J., Sobrino, J. A., Calera, A., Montero, F., and Cisneros, J. M.: The Measurments Programme at Barrax, DAISEX Final Results Workshop, ESTEC, Holland, 15-16 March, ESA Publications Division, SP499, 43-51, 2001.

Moreno, J., Alonso, L., Fernndez, G., et al.: The SPECTRA Barrax Campaign (SPARC): Overview and first results from CHRIS data, in: Proceedings of 2nd CHRIS/PROBA Workshop, Frascati, Italy, ESA-ESRIN, CD-ROM, 2004.

Qin, Z., Karnieli, A., and Berliner, P.: A mono-window algorithm for retrieving land surface temperature from Landsat TM data and its application to the Israel-Egypt border region, Int. J. Remote Sens., 22(18), 3719-3746, 2001.

Quattrochi, D. A. and Luvall, J. C.: Thermal infrared remote sensing data for analysis of landscape ecological processes: methods and applications, Landscape Ecol., 14(6), 577-598, 1999.

Roerink, G., Su, Z., and Menenti, M.: S-SEBI: A Simple Remote Sensing Algorithm to Estimate the Surface Energy Balance, Phys. Chem. Earth Pt. B, 25(2), 147-157, 2000.

Seguin, B. and Itier, B.: Using midday surface temperature to estimate daily evaporation from satellite thermal IR data, Int. J. Remote Sens., 4(2), 371-383, 1983.

Sobrino, J. A. and Raissouni, N.: Toward remote sensing methods for land cover dynamic monitoring: application to Morocco, Int. J. Remote Sens., 21(2), 353-366, 2000.

Sobrino, J. A., Gómez, M., Jiménez-Muñoz, J. C., Olioso, A., and Chehbouni, G.: A simple algorithm to estimate evapotranspiration from DAIS data: Application to the DAISEX Campaigns, J. Hydrol., 315, 117-125, 2005.

Sobrino, J. A., Jiménez-Muñoz, J. C., Zarco-Tejada, P. J., SepulcreCantó, G., and de Miguel, E.: Land surface temperature derived from airborne hyperspectral scanner thermal infrared data, Remote Sens. Environ., 102, 99-115, 2006.

Wassenaar, T., Olioso, A., Hasager, C., Jacob, F., and Chehbouni, A.: Estimation of evapotranspiration on heterogeneous pixels, in: 1st Recent Advances in Quantitative Remote Sensing, edited by: Sobrino, J. A., Torrent (Valencia), Spain, 16-20 September, Publicacions de la Universitat de València, 458-465, 2002. 